[Contribution from the Division of Drugs, Bureau of Chemistry, U. S. DEPARTMENT OF AGRICUI,TURE.]

\title{
THE USE OF ORGANIC SOLVENTS IN THE QUANTITATIVE SEPARATION OF METALS. III. THE SEPARATION OF MAGNESIUM FROM SODIUM AND POTAS- SIUM CHLORIDES.
}

\author{
BY S. PALKIN.
}

Received Jane 14, 1920。

In a previous communication, ${ }^{1}$ the author has shown that sodium and potassium chlorides can be quantitatively precipitated from an acidified water solution by the use of alcohol and ether. Advantage was taken of this fact to effect a separation of these alkali metals from their third member, lithium, as the chloride of the latter is readily soluble in a mixture of alcohol and ether. Experiments with magnesium chloride have shown that this salt too is soluble in an alcohol-ether mixture and can be separated easily from the chlorides of sodium and potassium, using essentially the same procedure as that outlined for the separation of lithium from the other alkali metals.

The only method on record, involving the use of an organic solvent for the separation of magnesium from the alkali metals, is that of Gooch and Fddy. ${ }^{2}$ In this method a solution of ammonia and ammonium carbonate in alcohol is used to precipitate the magnesium, while the alkali chlorides (except lithium) are determined in the filtrate.

Like the Gooch-Eddy separation, the alcohol-ether method herein proposed, makes it possible to determine magnesium and the alkalies in the same sample, with the additional advantage that the reagents used are readily volatile on the steam bath and the precipitate is that of the alkali chlorides instead of magnesium (as is the case in other methods), thus making it possible to secure a more rapid and direct determination of the alkali metals, where that is particularly desired. The magnesium may then be determined in the filtrate.

Very pure magnesium chloride was prepared by further purification of c. Ir. magnesium chloride obtained in the market. This was done in order to free it from traces of alkali chlorides and other substances insoluble in alcohol-ether mixture. In like manner samples of c. P. sodium chloride and potassium chloride, respectively, were treated to remove traces of magnesium chloride and other substances soluble in alcoholether mixture. The method of purification used was essentially the method of separation here described. Alcoholic solutions of the pure magnesium chloride were prepared and an aliquot portion pipetted off for

\footnotetext{
1 This Journal, 38, 2326 (I916).

'Am.J. Science, 25, 444 (1908).
} 
each experiment. Errors of volume change due to temperature were elimainated by making all pipetting at the same temperature.

A mixture of equal weights of the pure dried sodium and potassium chlorides was used and the required amount weighed out for each experiment.

The following is a table of results obtained by the proposed method, using various proportions of tnagnesium and alkali chlorides. In some experiments values obtained in the first precipitation are recorded in addition to the value of the total alkali chlorides by the two precipitations.

Risults Obtainfod by Proposed METhod.

\begin{tabular}{|c|c|c|c|c|c|}
\hline \multirow[b]{2}{*}{ Fxpt. } & \multicolumn{2}{|c|}{ Weight $\mathrm{NaCl}, \mathrm{KCl}$. } & \multicolumn{2}{|c|}{$\begin{array}{l}\text { Weight } \mathrm{Mg}_{22_{2} \mathrm{O}_{7}} \\
\text { due to } \mathrm{MgCl}_{2} \text { solution. }\end{array}$} & \multirow{2}{*}{$\begin{array}{l}\text { Wt. NaCl, } \mathrm{KCl} \\
\text { found by first } \\
\text { precipitation } \\
\text { G. }\end{array}$} \\
\hline & $\begin{array}{c}\text { Used. } \\
\text { G. }\end{array}$ & $\begin{array}{l}\text { Found. } \\
\text { Q. }\end{array}$ & $\begin{array}{l}\text { Used.c. } \\
\text { Q. }\end{array}$ & $\begin{array}{c}\text { Found. } \\
\text { G. }\end{array}$ & \\
\hline$x \ldots \ldots \ldots \ldots$ & 0.5000 & 0.4996 & 0.0070 & 0.0078 & $\ldots$ \\
\hline $2 \ldots \ldots \ldots \ldots$ & 0.3800 & 0.3795 & $0 . \times 743$ & 0.1748 & $\ldots$ \\
\hline $3 \ldots \ldots \ldots$ & 0.2500 & 0.2499 & 0.3486 & 0.3483 & $\cdots$ \\
\hline $4 \ldots . . . . .$. & 0.5000 & 0.4995 & 0.0060 & 0.0067 & $\ldots$ \\
\hline $5 \ldots \ldots \ldots$ & 0.3800 & 0.3801 & $0.150 \mathrm{r}$ & 0.1500 & $\ldots$ \\
\hline $6 \ldots \ldots \ldots$ & 0.2500 & 0.2505 & 0.3002 & 0.3017 & $\ldots$ \\
\hline$y, \ldots \ldots \ldots$ & 0.0500 & 0.0503 & 0.3004 & 0.3006 & $\ldots$ \\
\hline $8 \ldots \ldots \ldots$ & 0.5000 & 0.5005 & 0.0300 & 0.0307 & 0.4960 \\
\hline $9 \ldots \ldots \ldots$ & 0.5000 & 0.5005 & 0.0300 & 0.0302 & 0.4965 \\
\hline $10, \ldots \ldots . .$. & 0.5000 & 0.5000 & 0.0300 & 0.0304 & 0.4990 \\
\hline$x \ldots \ldots \ldots \ldots$ & 0.4000 & 0.4006 & 0.1147 & 0.1157 & 0.3989 \\
\hline$\$ 3 \ldots \ldots \ldots$ & 0.3000 & 0.3004 & 0.2294 & Spattered, & 0.2978 \\
\hline $13 \ldots \ldots \ldots$ & 0.1000 & 0.1002 & 0.4587 & 0.4577 & 0.0970 \\
\hline $14 \ldots \ldots \ldots . .$. & 0.2500 & 0.2500 & 0.2293 & 0.2286 & 0.2477 \\
\hline $15, \ldots \ldots \ldots$ & 0.5000 & 0.5000 & 0.0229 & 0.0227 & 0.4947 \\
\hline$x 6 \ldots \ldots \ldots$ & 0.0500 & 0.0506 & 0.2748 & 0.2746 & $\ldots$ \\
\hline $17 \ldots . . . .$. & 0.5000 & 0.5003 & 0.0055 & 0.0058 & $\ldots$ \\
\hline $18 \ldots \ldots \ldots$ & 0.2000 & 0.2001 & 0.0054 & 0.0056 & $\ldots$ \\
\hline$\pi 9 \ldots \ldots \ldots$ & 0.5000 & 0.5002 & 0.0599 & 0.0610 & 0.4983 \\
\hline $20, \ldots \ldots \ldots$ & 0.5000 & 0.5008 & 0.0599 & 0.0605 & 0.4950 \\
\hline $4 x \ldots \ldots \ldots$ & 0.5000 & 0.5005 & o. $x 498$ & o. $x 49 \pi$ & 0.4945 \\
\hline $22 \ldots \ldots \ldots \ldots$ & 0.4500 & 0.4499 & 0.0990 & 0.0977 & 0.4474 \\
\hline $23 \ldots \ldots \ldots$ & 0.3800 & 0.3805 & 0.2476 & c. 2480 & $0.379 \mathrm{r}$ \\
\hline $24 \ldots \ldots \ldots$ & 0.2500 & 0.2509 & $0.495^{2}$ & 0.4955 & 0.2476 \\
\hline $25 \ldots \ldots \ldots \ldots$ & 0.0050 & $0.005 \mathrm{I}$ & 0.4952 & 0.4960 & $\ldots$ \\
\hline
\end{tabular}

Method.

The total chlorides of magnesium, sodium and potassium are dissolved in a minimum amount of cold water in a roo-r 50 cc. beaker-flask. Abott $1.5 \mathrm{cc}$. is sufficient for $0.5 \mathrm{~g}$. of salt. ${ }^{1}$ When all is in solution, one drop of conc hydrochloric acid is added and, gradually, $25 \mathrm{cc}$. of absolute alcohol, the alcohol being dropped into the center of the beaker (not on the

1 The magnesium chloride content should not exceed $0.3 \mathrm{~g}$. and the total chlorides 0.58 . 
sides) while rotating. The sodium and potassium chlorides should precipitate in a perfectly uniform granular condition. In a similar manner, while rotating the flask, $25 \mathrm{cc}$. of U.S. P. ether is added and the mixture is allowed to stand about 5 minutes or until the precipitate is agglomerated and the supernatant liquid almost clear. If there is any tendency for the precipitate to become gelatinous, a few cc. of absolute alcohol is added and the flask rotated. This tendency to gel occurs only when a relatively large amount of magnesium chloride is present and an excessive amount of moisture has been introduced.

The mixture is then filtered through a weighed Gooch crucible into a I $50 \mathrm{cc}$. Erlenmeyer flask, using a bell-jar arrangement and permitting only mild suction, in order to avoid sucking the precipitate dry too soon. ${ }^{1}$ The beaker-flask is thoroughly washed with a mixture of one part alcohol and 4 parts ether, and adhering particles of salt are removed with the aid of a rubber-tipped rod. The precipitate in the Gooch crucible is also well washed and the crucible set aside.

The filtrate is evaporated to dryness on the steam bath (using air-blast if available). The residue is taken up with Io $\mathrm{cc}$. of absolute alcohol, warming if necessary, so that nearly everything passes into solution, and one drop of conc. hydrochloric acid is added. If a slight film remains on the bottom of the flask and sides, it is loosened by rubbing with a rubbertipped rod. A fine powder of sodium and potassium chloride (a few mg.) will probably separate. While rotating the flask $50 \mathrm{cc}$. of U.S. P. ether is added gradually and the mixture allowed to stand for about 20 minutes. This is then filtered through the original Gooch crucible containing the bulk of sodium and potassium chlorides, into a tall beaker (about $250 \mathrm{cc}$ ). The same careful precautions are taken as outlined in the first filtration. The crucible containing the sodium and potassium chlorides is dried, gently ignited, cooled and weighed.

\section{Determination of the Magnesium.}

The filtrate containing the magnesium chloride is evaporated on the steam bath to dryness, or nearly so, using air-blast if available. It is then taken up with 5 to ro cc. of conc. hydrochloric acid, the requisite amount of water and sodium hydrogen phosphate added and the magnesium determination made in the usual way. The crystalline form of the magnesium ammonium phosphate is obtained much more readily if the precipitate first formed with the ammonia is redissolved with hydrochloric acid, and then neutralized a second time by the very gradual addition of the ammonia with constant stirring until most of the precipitate has formed, after which excess of ammonia is added.

1 This filtration can best be accomplished by using a 2-hole rubber stopper for the funnel, and covering up the second hole with the finger while filtering, then releasing the suction by removal of the finger as soon as desired. 


\section{Summary.}

The author's method for the separation of lithium from the other alkali metals has been studied with the view to its adaptability to the separation of magnesium from these metals. With some modifications, the procedure has been found to be well adapted to magnesium. The method depends on the progressive precipitation of the sodium and potassium chlorides from a concentrated aqueous solution by the use of alcohol and ether and is divided into 2 stages, ( $\mathrm{r}$ ) in which all but a few $\mathrm{mg}$. is precipitated, and (2) in which the last few mg. is removed from solution.

The method has several advantages, viz., (I) it affords a direct determination of the sodium and potassium chlorides in that they are precipitated firsi (rather than after magnesium as in other methods), (2) the reagents used are readily volatile organic solvents, and (3) no foreign base or salts is introduced as a precipitating agent.

WASTINGTON, D. C.

[CONTRIBdTion From the WOLCOTT GibBs Memorial IAaboRatory, Harvard UNIVERSITY.]

\section{AN INDIRECT METHOD OF DETERMINING THE SPECIFIC HEAT OF DILUTE SOLUTIONS, WITH PRELIMINARY DATA CONCERNING HYDROCHLORIC ACID.}

By Thedore W. Richards and Alian W. Rowh.

Received June 16, 1920.

\section{Method and Apparatus.}

The specific heat of a dilute solution can be determined indirectly from the difference in the heat evolved on diluting a known concentrated solution to a solution of the desired strength at 2 different temperature. ${ }^{1}$ This method rests upon the familiar consequence of the first law of thermodynamics known as Kirchhof's Law, viz.,

$$
K_{M}-K_{M}^{\prime}=\left(U^{\prime}-U\right) / \Delta \theta
$$

In this equation $K_{M}$ and $K^{\prime}{ }_{M}$ represent, respective, the molal heat capacities of the reacting stubstances and of the products, and $U$ and $U^{\prime}$ the re-

${ }^{1}$ Berthelot pointed this out long ago, but did not test it experimentally (Mecanigue chimique, $x, 278$ (1879)). Perhaps the first experimental application of the principle has been made by one of us and A, B. Lamb, Proc. Am. Acad. 40.675 (rgos). As these authors pointed out, the process is a very accurate one, the errors being divided instead of multiplled by it. Tucker's interesting work deals primarily with corn. centrated solutions (Phil. Trans. [A] 215, 319 (I915)). This was published some time after the present work (the publication of which was much delayed by the war) was completed. The "continuous flow" method used for heats, of neutralization by J. B. Dickson at the suggestion of A. A. Noyes and under the direction of F. G. Keyes might be used for work of this kind, but has not yet been so employed (Thesis submitted to Faculty of Mass. Inst. Tech., rgr 7 ). 